Article

\title{
Anti-Browning and Oxidative Enzyme Activity of Rice Bran Extract Treatment on Freshly Cut 'Fuji' Apple
}

\author{
Sang Hoon Lee ${ }^{1,2}$, Soo Min Baek ${ }^{3}$, Inhye Jeong ${ }^{1,2}$, Wan Heo ${ }^{4}$, Kyung-A Hwang ${ }^{5}$, Bok Kyung Han ${ }^{1, *}$ \\ and Young Jun Kim ${ }^{1,2, *}$
}

check for

updates

Citation: Lee, S.H.; Baek, S.M.; Jeong, I.; Heo, W.; Hwang, K.-A.; Han, B.K.; Kim, Y.J. Anti-Browning and Oxidative Enzyme Activity of Rice Bran Extract Treatment on Freshly Cut 'Fuji' Apple. Agronomy 2022, 12, 86. https://doi.org/10.3390/ agronomy12010086

Academic Editors: Riccardo Testa, Giuseppina Migliore, Giorgio Schifani and József Tóth

Received: 25 November 2021 Accepted: 27 December 2021 Published: 30 December 2021

Publisher's Note: MDPI stays neutral with regard to jurisdictional claims in published maps and institutional affiliations.

Copyright: (C) 2021 by the authors. Licensee MDPI, Basel, Switzerland. This article is an open access article distributed under the terms and conditions of the Creative Commons Attribution (CC BY) license (https:// creativecommons.org/licenses/by/ $4.0 /)$.
1 Department of Food and Biotechnology, Korea University, Sejong 30019, Korea; t9592359@korea.ac.kr (S.H.L.); isaac36@korea.ac.kr (I.J.)

2 BK21 FOUR Research Education Team for Omics-Based Bio-Health in Food Industry, Korea University, Sejong 30019, Korea

3 Program in Converging Technology Systems and Standardization, Korea University, Sejong 30019, Korea; kwin572@naver.com

4 Department of Food and Nutrition, Seowon University, Cheongju 28674, Korea; 01062033526@seowon.ac.kr

5 Department of Agrofood Resources, National Institute of Agricultural Sciences, Rural Development Administration, Wanju-gun 55365, Korea; kah366@korea.kr

* Correspondence: hanmoo@korea.ac.kr (B.K.H.); yk46@korea.ac.kr (Y.J.K.)

Abstract: Preserving the quality of freshly cut fruits is essential for food marketing. This study aimed to evaluate the anti-browning effect of rice bran extract (RE) added to a vitamin C mixture (VCM), which is widely used as an anti-browning agent. Freshly cut apples were prepared using the following processes: raw material selection, washing, cutting, soaking, and packaging. A comparison of cut apples soaked with 3\% VCM combined with 1\% RE (VR) and cut apples treated with 4\% VCM showed that the $\mathrm{L}^{*}$ and BI values had similar levels. After 12 days of storage, the amount of yeast and mold in cut apples after $4 \%$ VCM and VR treatment was $6.15 \times 10^{4} \pm 0.48 \mathrm{CFU} / \mathrm{mL}$ and $4.25 \times 10^{3} \pm 0.15 \mathrm{CFU} / \mathrm{mL}$, respectively, and the degree of bacterial growth was reduced by VR treatment. On day 12 of storage, the activities of polyphenol oxidase (PPO) and peroxidase (POD) were similar in the 4\% VCM and VR groups. The polyphenol content was significantly higher in the VR group $(121.0 \pm 2.2)$ than in the $4 \%$ VCM group $(76.9 \pm 2.2)$. These results indicate that VR treatment for freshly cut apples is a potential alternative to $4 \%$ VCM treatment, with an effective anti-browning capacity and improved polyphenol content.

Keywords: freshly cut apple; rice bran extract; vitamin $C$ mixture; polyphenol oxidase; peroxidase

\section{Introduction}

Recently, the industry for supplying fresh fruits and vegetables has grown rapidly as consumer preference and demand for fresh and healthy foods have increased [1]. Research on efficient preservation methods for freshly cut apples is drawing attention for its potential to reduce the processing costs in the fresh produce industry [2]. Freshly cut apples deteriorate rapidly as a result of enzymatic browning [3], tissue softening [4], and microbial growth [5]. In particular, fleshly cut apples may undergo browning during the production process such as washing, peeling, coring, cutting, and storage, which affects the flavor, texture, and microbial growth of the product [3]. Freshly cut products are, therefore, susceptible to microbial growth, which ultimately shortens the shelf life [6]. Therefore, extending shelf life by preventing surface browning has been a focus in the freshly cut industry in recent decades [7].

There have been many studies on antioxidants such as ascorbic acid, calcium ascorbate [8], sodium chloride [9], and citric acid [10] in relation to browning inhibition. Among them, ascorbic acid was known as a substance with excellent antioxidant activity and is often used to control discoloration [11]. Therefore, commercially anti-browning agents 
usually contain ascorbic acid. Among them, vitamin C mixture (VCM) supplementation is most widely used.

Polyphenol oxidase (PPO) and peroxidase (POD) are present in plants, animals, fungi, and bacteria [12,13] and induce polyphenol oxidation, leading to enzymatic browning and a reduction of phenolic compounds in apples [14]. Enzymatic browning is the result of the PPO-catalyzed hydroxylation of monophenols to diphenols and the oxidation of diphenols to quinones [15]. This activity could be successfully suppressed by applying antioxidants or chelating reagents [16].

Rice bran is the most produced by-product of the rice milling industry with approximately 29.3 million tons produced per year [17]. It has attracted global attention due to various advantages such as nutritious composition, easy availability, low cost, high antioxidant potential, and promising effects on several metabolic diseases [18]. In addition, rice bran is rich in natural antioxidants such as phenolic acids and bioactive phytochemicals [19]. Among the various types of phenolic acids contained in rice bran, phytic acid acts as a chelating agent to inhibit PPO activity [20]. Various health benefits of natural antioxidants were reported [21]. By combining rice bran with VCM, economic and health benefits can be expected.

To date, several studies have investigated the anti-browning effect of natural substances in combination with ascorbic or citric acid on apples or apple puree [22,23]. Although there have been several reports of organic acid treatment alone [24], few studies have been conducted to inhibit browning by combining natural by-products such as rice bran.

Therefore, in this study, an optimal combination for freshly cut apples was established by adding RE to VCM. In addition, the functional improvement of VCM combined with RE (VR) as an anti-browning agent was confirmed

\section{Materials and Methods}

\subsection{Sample Preparation and Treatments}

"Fuji" apples with uniform size, color, and ripeness without apparent damage were selected from a local wholesale distributor (Cheongju, Korea). The apples were washed with tap water and wiped before use. After removing the seeds, the apples were each cut into eight slices of similar size and shape, followed by soaking in the distilled water (DW) or anti-browning treatment solution, which was VCM, RE and VCM combined with RE, for $1 \mathrm{~min}$. VCM (FOOD freshly ${ }^{\circledR}$; Food Freshly AFC, Bielefeld, Germany) was dissolved in distilled water at 3\% and $4 \%(w / w)$. Rice bran extract (RE; Tsuno Rice Fine Chemicals Co. Ltd., Wakayama, Japan) was purchased standardized with $42.3 \%$ phytic acid and was diluted with $0.8,1$, and $1.2 \%$. After soaking, the apples were dried at a wind speed of 3.5 $\mathrm{m} / \mathrm{s}$ for $40 \mathrm{~s}$ and stored under refrigerated conditions $\left(4^{\circ} \mathrm{C}\right)$. The resulting apple slices were used for subsequent experiments.

\subsection{Color Analyses}

The color of four apple slices per group was measured daily for 12 days using a colorimeter (Chroma Meter CR-400; Konica Minolta, Tokyo, Japan) on Illuminant D65 mode with white tile calibration. The color of DW-, 3\% and 4\% VCM-, and 3\% VCM combined with $0.8,1.0,1.2 \%$ RE-coated apple slices was measured $(n=4)$. Standard tristimulus CIE $\mathrm{L}^{*}, \mathrm{a}^{*}$, and $\mathrm{b}^{*}$ values were obtained using the colorimeter. The browning index (BI) was calculated from the CIE $\mathrm{L}^{*} \mathrm{a}^{*} \mathrm{~b}^{*}$ parameters according to the following equations, as previously described [25]:

$$
\begin{aligned}
& \mathrm{X}=\left(\mathrm{a}+1.75 \times \mathrm{L}^{*}\right) \div\left(5.645 \times \mathrm{L}^{*}+\mathrm{a}^{*}+3.012 \times \mathrm{b}^{*}\right) \\
& \mathrm{BI}=100 \times(\mathrm{X}-0.31) \div 0.172 \\
& \Delta \mathrm{BI}=\mathrm{BI} t-\mathrm{BI} 0(\mathrm{BI} t=\mathrm{BI} \text { value at time } t, \mathrm{BI} 0=\text { initial } \mathrm{BI} \text { value })
\end{aligned}
$$

\subsection{Weight Loss}

The three apple slices per group were measured for weight loss every 3 days for 12 days $(n=3)$. It was assumed that the weight loss was entirely consistent with water 
loss, which is essential for assessing the quality of apples [25]. The weight loss value was determined by the moisture loss of all the tested treatment materials. The weights of the apples were individually monitored with an analytical balance on days $0,3,6,9$, and 12 during the storage period. The weight loss ratio W (\%) was calculated as follows:

$$
\mathrm{W}(\%)=(\mathrm{mi}+\mathrm{mt}) \div \mathrm{mi} \times 100 \%
$$

where mi is the initial weight and $\mathrm{mt}$ is the weight at the end of the storage period.

\subsection{Total Soluble Solid Content and Titratable Acidity}

The apple slice per group for total soluble solid content (SSC) and acidity was measured every 3 days for 12 days for the group of DW-, 4\% VCM-, and VR-coated apple slices $(n=3)$. Each SSC was estimated using a digital refractometer (PAL-1; ATAGO, Tokyo, Japan) from apple juice obtained by squeezing apple slices. Each value represents the average of the six independent replicates. SSC measurements were performed on the same fruit portion and expressed in ${ }^{\circ} \mathrm{Brix}$, and $\mathrm{pH}$ was measured with a $\mathrm{pH}$ meter (Orion Star A211 $\mathrm{pH}$ benchtop meter; Thermo Scientific ${ }^{\mathrm{TM}}$; Waltham, MA, USA). The titratable acidity was determined by titrating apple juice with $0.1 \mathrm{M} \mathrm{NaOH}$ to $\mathrm{pH}$ 8.2. Titratable acidity was calculated using the following equation:

$$
\text { Titratable acidity }(\%)=\left(\mathrm{E} \times \mathrm{V} \_\mathrm{NaOH} \times 100\right) / \mathrm{W}
$$

where $\mathrm{E}$ is the equivalent of malic acid, $\mathrm{V}$ is the volume of titrant used $(\mathrm{NaOH})$, and $\mathrm{W}$ is the sample weight $(\mathrm{g})$.

\subsection{Total Phenolic Content}

The total phenolic content (TPC) for the apple slices in each group was measured every 3 days for 12 days. The TPC of DW-, $4 \%$ VCM-, and 3\% VCM combined with $1.0 \%$ RE (VR)coated apple slices were measured $(\mathrm{n}=3)$. After pressing $15 \mathrm{~g}$ of apples, supernatant was filtered using a $0.45 \mu \mathrm{m}$ filter (Z672661; Whatman, Maidstone, UK). TPC was determined as previously described [26]. Folin-Ciocalteu reagent $(1 \mathrm{~mL})$ was added to the diluted supernatant (1:9 $v / v$ in distilled water). After $5 \mathrm{~min}$, sodium carbonate $(10 \mathrm{~mL}, 70 \mathrm{~g} / \mathrm{L})$ was added, and distilled water was added to make a final volume of $25 \mathrm{~mL}$. The mixture was shaken and left for $2 \mathrm{~h}$ in the dark at approximately $20^{\circ} \mathrm{C}$. The phenolic content was calculated from the absorbance at $760 \mathrm{~nm}$ using a spectrophotometer (UV-1800; Shimadzu Corp., Kyoto, Japan). The absorbance was compared to a standard curve prepared using gallic acid. The results were obtained in triplicate and expressed as gallic acid equivalent (GAE)/ kg fresh weight of ground apples.

\subsection{Total Protein and Oxidative Enzyme Activity Assays}

The apple slices in each group were measured for their total protein and enzyme activity every 3 days for 12 days. The group of DW-, 4\% VCM-, and VR-coated apple slices were measured $(n=3)$. Total protein was analyzed to adjust the protein concentration. PPO and POD activities were tested using a previously reported method $[27,28]$. Lysis buffer was prepared using a $0.2 \mathrm{M}$ sodium phosphate buffer (SPB) at $\mathrm{pH} 6.5$ containing $4 \%$ $(w / w)$ polyvinylpolypyrrolidone and $1 \%(w / w)$ Triton X-100. Then, $20 \mathrm{~mL}$ of lysis buffer was added to $10 \mathrm{~g}$ of homogenized apples for $3 \mathrm{~min}$. After centrifugation at $12,000 \times \mathrm{g}$ for $20 \mathrm{~min}$, the supernatant was filtered and used as an apple enzyme extract. The protein concentration of the apple enzyme extracts was determined using the Bradford assay [29]. The changes in the PPO and POD activities in the absorbance $/ \mathrm{min} / \mathrm{g}$ FW of the sample were expressed as the activity of the apple enzyme extract. All analyses were performed in triplicate, and a freshly prepared substrate solution was used for each enzyme activity analysis. The substrate solution contained $0.07 \mathrm{M}$ catechol in $3 \mathrm{~mL}$ of $0.05 \mathrm{M}$ sodium phosphate buffer ( $\mathrm{pH}$ 6.5) solution. First, $0.2 \mathrm{~mL}$ of the apple enzyme extract was mixed with $1.5 \mathrm{~mL}$ of $40 \mathrm{mM} / \mathrm{L}$ catechol and $2.3 \mathrm{~mL}$ of $0.2 \mathrm{M}$ SPB solution. The absorbance of 
the mixture was measured immediately at $420 \mathrm{~nm}$ for 10 min using a spectrophotometer in the kinetic mode for PPO activity. POD activity was measured using an assay mixture containing $0.5 \mathrm{~mL}$ of apple enzyme extract, $2.3 \mathrm{~mL}$ of $0.2 \mathrm{M}$ SPB solution, $0.15 \mathrm{~mL}$ of $98 \%$ Guaiacol, and $0.05 \mathrm{~mL}$ of $9.8 \mathrm{M} \mathrm{H}_{2} \mathrm{O}_{2}$. The absorbance of the mixture was measured immediately at $470 \mathrm{~nm}$ for $10 \mathrm{~min}$ using a spectrophotometer (UV-1800; Shimadzu Corp., Kyoto, Japan) in kinetic mode for POD activity.

\subsection{Microbial Counts}

The microbial counts for the apple slices in each group was measured every 3 days for 12 days. The group of DW-, 4\% VCM-, 1\% RE-, and VR-coated apple slices were measured $(\mathrm{n}=3)$. To calculate the microbial counts, methods described in previous studies were used [30,31]. Briefly, $10 \mathrm{~g}$ of each sample was combined with $90 \mathrm{~mL}$ of sterile peptone water in a filter bag (PX0020P; ELMEX, Nakano, Japan). The apples were homogenized in a stomacher for $3 \mathrm{~min}$. Then, $1 \mathrm{~mL}$ of the sample solution was placed on an appropriate dried medium. The sample solution was spread on a film (3M Petri film E. coli/Coliform Count Plates; 3M, Saint Paul, MN, USA) and incubated at $35^{\circ} \mathrm{C}$. The surviving E. coli cell population $(\log \mathrm{CFU} / \mathrm{g})$ was counted after $24 \mathrm{~h}$. The growth of yeasts and molds was determined 3 days after inoculation into the films at $25^{\circ} \mathrm{C}$.

\subsection{Sensory Test}

The sensory quality of the coated freshly cut apples was tested on 34 people aged from 20 to 50 years. Preference evaluation was conducted in five categories: overall acceptability, color, texture, sweet taste, and sour taste. Scores for each quality were graded in a preference range from 1-9. Apples were treated with 4\% VCM and 3\% VCM $+1.0 \%$ RE solutions and stored in a refrigerator for $24 \mathrm{~h}$. Freshly cut apples were marked with random numbers to exclude bias in the evaluation of preference, and the order of each apple was also randomly arranged and evaluated.

\subsection{Statistical Analysis}

The experiment had a dual-factor (treatment $\times$ storage period) design with an analysis of variance (ANOVA) using SPSS software (Version 25, IBM, NY, USA). Statistical significance was assessed at $p=0.05$, and means were separated using Duncan's multiple range test. Correlation analysis was performed using a two-tailed Pearson's correlation test [32].

\section{Results and Discussion}

\subsection{Effects of Anti-Browning Reagent Mixture on Browning Index}

In general, commercially available VCM is applied at $4 \%(w / w)$ for apple processing to prevent browning, and the shelf life of freshly cut apples is known to be up to 7 days. Since the initial color values of apples differ even within the same variety, the browning index (BI) was calculated as delta BI and used for comparison (Figure 1). When freshly cut apples were treated with RE alone, their acidities were high (Table 1). Therefore, freshly cut apples were treated with a mixture of VCM and RE to control $\mathrm{pH}$. In the case of the DW treatment group, the initial BI value increased within a day. There were no significant differences between 3\% VCM and 4\% VCM treatment. All of the mixtures of VCM and RE showed a similar degree of protection against browning as 4\% VCM (Figure 1). VCM can eliminate oxygen, an electronic donor in the anti-browning mechanism.

VCM is composed of calcium chloride, potassium citrate, and ascorbic acid. By containing salt, the $\mathrm{pH}$ may be lowered compared to the conventional treatment with ascorbic acid alone [33]. When mixing according to the concentration for the combination of VCM and RE, salt was formed when 3\% VCM and 0.5\% RE were mixed (data not shown). The reason for the formation of salts is that the $\mathrm{pH}$ decreases when VCM was combined with RE. At this time, if the $\mathrm{pH}$ is not sufficiently reduced, calcium and potassium metal cations in VCM combined with hydroxide to form a salt [34]. Therefore, the experiments were conducted with $0.8 \%, 1 \%$, and $1.2 \% \mathrm{RE}(w / w)$. According to the data of the last test 
day, a tendency to inhibit browning was observed with 4\% VCM in all groups except the DW group.

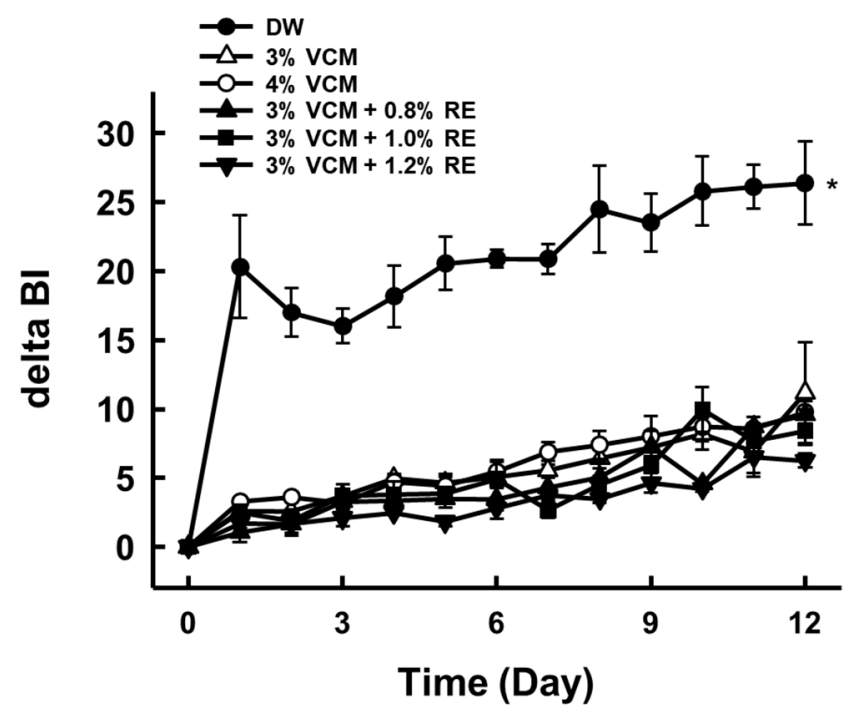

Figure 1. Evaluation of browning index over storage period. Freshly cut apples were treated with anti-browning agent for $1 \mathrm{~min}$, followed by measurement of the $\Delta \mathrm{BI}$ values for 12 days. Statistical significance was determined by one-way ANOVA (mean $\pm \mathrm{SE}, \mathrm{n}=4$ ).

Table 1. Measurement of $\mathrm{pH}$ values of the anti-browning agent solution.

\begin{tabular}{cc}
\hline Anti-Browning Agent & pH \\
\hline Apple juice & $4.30 \pm 0.01$ \\
DW & $4.97 \pm 0.02 *$ \\
100\% RE & $0.10 \pm 0.02 *$ \\
3\% VCM & $5.32 \pm 0.01^{*}$ \\
$4 \%$ VCM & $5.28 \pm 0.04^{*}$ \\
$3 \%$ VCM + 0.8\% RE & $4.37 \pm 0.03 *$ \\
$3 \%$ VCM + $1.0 \%$ RE & $4.30 \pm 0.02$ \\
\hline
\end{tabular}

* Statistical significance was determined by one-way ANOVA (mean $\pm \mathrm{SE}, \mathrm{n}=3$ ).

Of the RE added at concentrations of $0.8 \%, 1 \%$, and $1.2 \%$, the group of $3 \% \mathrm{VCM}+1 \%$ $\mathrm{RE}$ was the most similar to the $\mathrm{pH}$ of apple juice ( $\mathrm{pH} 4.3$ ). Thus, $1 \% \mathrm{RE}$ added to $3 \% \mathrm{VCM}$, which is effective for browning and has the most similar acidity to that of apple juice, was used as the optimal concentration in subsequent experiments. According to apple browning studies, delta BI values were corrected to the initial apple color value [35]. As browning progresses, the $L^{*}$ values for brightness decrease, and $a^{*}$ for red and $b^{*}$ for yellow increase [36].

Thus, we evaluated the $\Delta \mathrm{BI}, \mathrm{L}^{*}$ (brightness), $\mathrm{a}^{*}$ (green to red), and $\mathrm{b}^{*}$ (blue to yellow) of the freshly cut apples (Figure 2). The color of the DW group was the darkest among the samples and there was no significant difference between the $4 \%$ VCM and VR groups. Between day 1 and 12, the $a^{*}$ values of the DW, VCM, and VR samples changed from -5.57 to $-1.20,-5.68$ to -4.50 , and -5.78 to -4.14 , respectively. Similarly, the $b^{*}$ values for the DW, VCM, and VR samples changed from 23.81 to $31.71,22.97$ to 27.64 , and 22.30 to 26.00, respectively. In other words, the DW group showed the greatest color change, while the VR group maintained a level similar to that of the 4\% VCM group. 


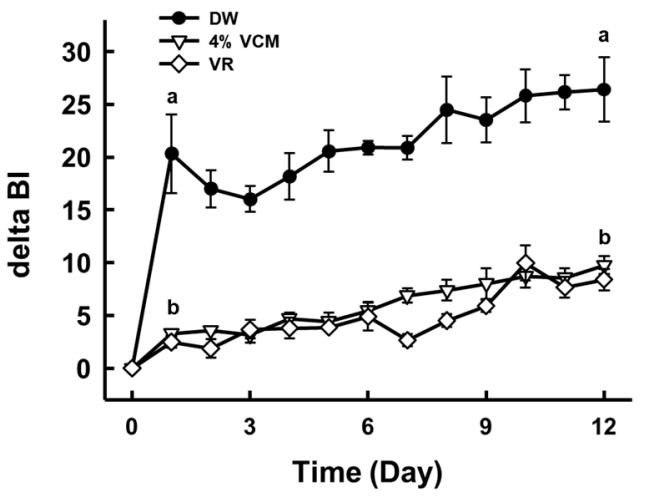

(a)

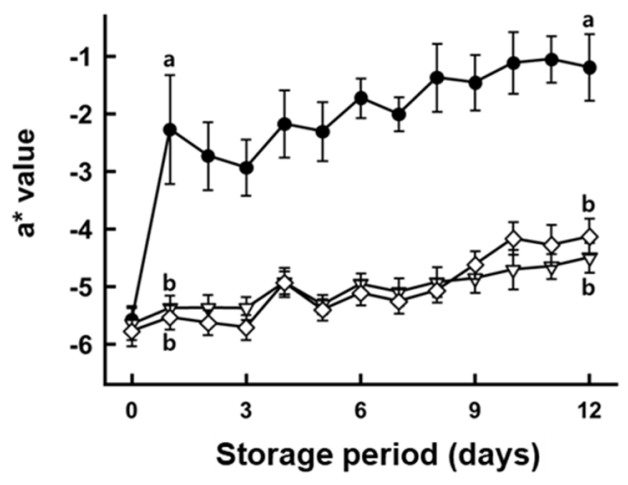

(c)

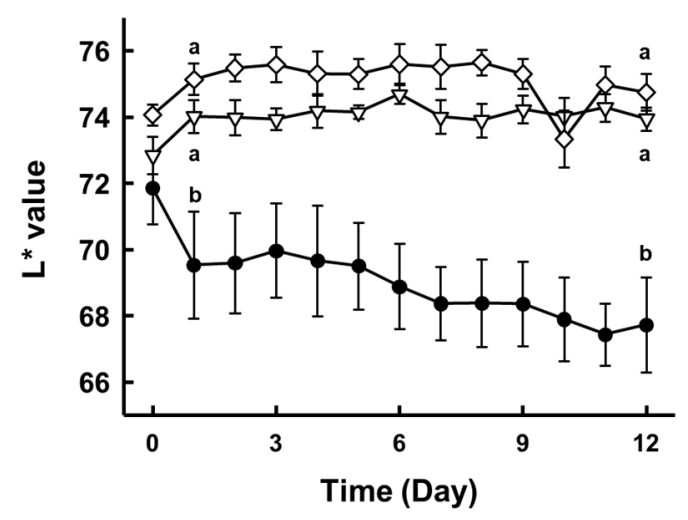

(b)

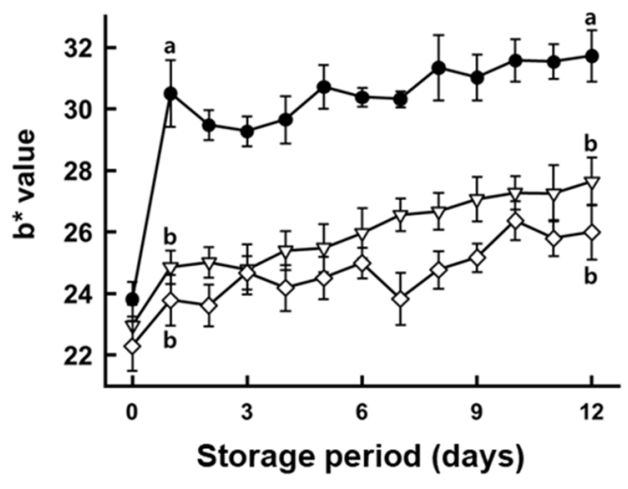

(d)

Figure 2. Changes in the color of freshly cut apples due to treatment with an anti-browning reagent. Changes in the color value of the apple cube surface according to various processing solutions for DW, 4\% VCM, and VR. (a) Delta BI value, (b) CIE L* value, (c) $a^{*}$ value, and (d) b* value. Statistical significance was determined by one-way ANOVA (mean $\pm \mathrm{SE}, \mathrm{n}=4$ ).

A previous study reported that decreasing $L^{*}$ values and increasing $a^{*}$ and $b^{*}$ values could be used as indicators of the browning reaction of freshly cut apples during storage [37]. The result of the DW group for the $L^{*}, a^{*}$, and $b^{*}$ values were similar to those of Chen et al., 2016 [38]. Both the 4\% VCM and the VR group exhibited an anti-browning effect as indicated by the reduction in the degree of the variations in $L^{*}, a^{*}$, and $b^{*}$ values.

\subsection{Effects of Anti-Browning Reagents on the Weight and Appearance of Apples}

The weight of coated freshly cut apples was measured to analyze the efficiency of the treatment effect to inhibit water loss during the experiment (Figure 3a). In previous studies, weight loss in apples was mainly due to a decrease in water content, and the decrease in other ingredients had a minor effect on weight loss [39].

In all the test groups, the weight of the apple slices gradually decreased over time. In particular, apples coated with 4\% VCM and VR showed reduced water loss compared to the DW group. The difference in weight loss results between the DW group and the VR group started to appear from day 9, at which time the DW, 4\% VCM, and VR groups showed a weight loss of $1.85 \pm 0.19 \%, 1.21 \pm 0.18 \%$, and $0.65 \pm 0.29 \%$, respectively. The lowest weight loss during the experiment was observed in the VR group. These results indicate that treated apples with a VR solution could prevent the loss of volatile apple components, including moisture. The picture shown in Figure $3 \mathrm{~b}$ was taken 3 days after the processing of the freshly cut apples, and the 4\% VCM and VR groups showed visual similarity. 


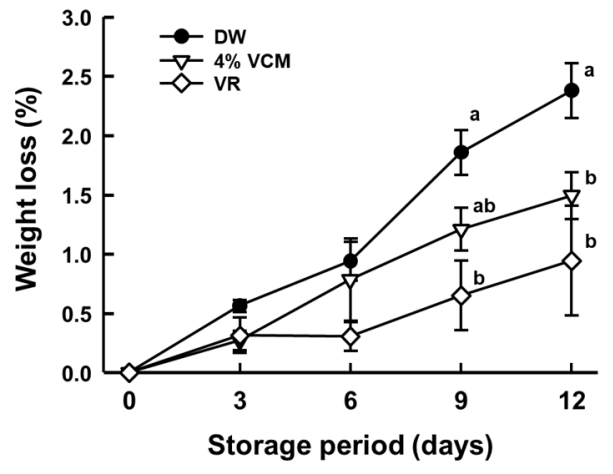

(a)

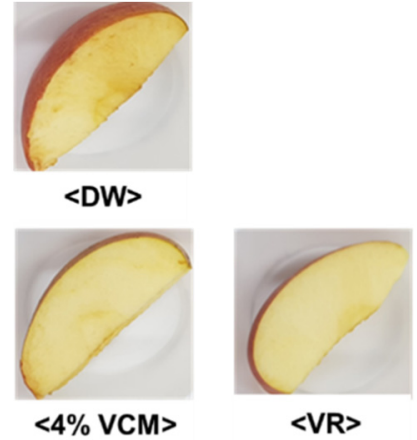

(b)

Figure 3. Change of weight loss and appearance of freshly cut apples. (a) Evaluation of weight loss in apples treated with DW, 4\% VCM, and VR for $1 \mathrm{~min}$. (b) Photographs of freshly cut apples according to the treatment conditions after 3 days. Statistical significance was determined using one-way analysis of variance (mean \pm standard error [SE], $\mathrm{n}=3$ ).

In addition, the $\mathrm{pH}$, Brix, and acidity values of the $\mathrm{DW}, 4 \% \mathrm{VCM}$, and VR groups were similar between day 0 and day 12 (Table 2). Therefore, none of the anti-browning agents tested in this study significantly affected the overall quality of apples.

Table 2. Changes in the $\mathrm{pH}$, Brix, and acidity of freshly cut apples.

\begin{tabular}{ccccccc}
\hline \multirow{2}{*}{ Group } & \multicolumn{5}{c}{ Storage Period (Days) } \\
\cline { 3 - 7 } & & $\mathbf{0}$ & $\mathbf{3}$ & $\mathbf{6}$ & $\mathbf{9}$ & $\mathbf{1 2}$ \\
\hline \multirow{3}{*}{$\mathrm{pH}$} & DW & $4.30 \pm 0.01$ & $4.26 \pm 0.07$ & $4.25 \pm 0.05$ & $4.26 \pm 0.06$ & $4.32 \pm 0.01$ \\
& $4 \%$ VCM & $4.30 \pm 0.03$ & $4.32 \pm 0.07$ & $4.27 \pm 0.06$ & $4.30 \pm 0.03$ & $4.32 \pm 0.06$ \\
& VR & $4.34 \pm 0.06$ & $4.31 \pm 0.05$ & $4.24 \pm 0.09$ & $4.32 \pm 0.03$ & $4.30 \pm 0.03$ \\
\hline \multirow{3}{*}{ Brix } & DW & $12.70 \pm 0.65$ & $13.20 \pm 0.20$ & $13.50 \pm 0.40$ & $12.67 \pm 0.40$ & $12.13 \pm 0.25$ \\
& 4 VCM & $13.23 \pm 0.29$ & $13.36 \pm 0.67$ & $13.30 \pm 0.40$ & $13.37 \pm 0.35$ & $13.17 \pm 0.49$ \\
& VR & $13.60 \pm 0.27$ & $13.37 \pm 0.31$ & $13.23 \pm 0.45$ & $13.70 \pm 0.30$ & $13.80 \pm 0.75$ \\
\hline \multirow{3}{*}{ Acidity } & DW & $0.22 \pm 0.01$ & $0.21 \pm 0.01$ & $0.26 \pm 0.01$ & $0.25 \pm 0.01$ & $0.23 \pm 0.01$ \\
& 4 VCM & $0.23 \pm 0.01$ & $0.22 \pm 0.01$ & $0.25 \pm 0.01$ & $0.24 \pm 0.01$ & $0.26 \pm 0.01$ \\
& VR & $0.23 \pm 0.01$ & $0.22 \pm 0.01$ & $0.23 \pm 0.01$ & $0.23 \pm 0.01$ & $0.28 \pm 0.01$ \\
\hline
\end{tabular}

Evaluation of $\mathrm{pH}$, Brix, acidity, Brix/acidity in freshly cut apples during storage at $4{ }^{\circ} \mathrm{C}$ every 3 days. Statistical significance was determined by one-way ANOVA (mean $\pm \mathrm{SE}, \mathrm{n}=3$ ).

\subsection{Effects of Anti-Browning Treatments on Total Polyphenol Content and Phenol Oxidase Enzyme Activity}

Polyphenols are the main substrates with which enzymatic browning reacts and are precursors to brown pigmentation. Total polyphenol content (TPC) and the activity of polyphenol oxidase (PPO) and peroxidase (POD) were measured. TPC was significantly higher in the VR group $(121.0 \pm 2.2)$ compared to both DW $(56.9 \pm 2.3)$ and $4 \%$ VCM $(76.9 \pm 2.2)$ on day 12 . In addition, as in the DW, the TPC was positively correlated with the PPO and POD with $\mathrm{r}$ values at 0.7444 and 0.7776 , respectively (Table S1; Supplementary Materials).

Ascorbic acid, a major component of $4 \% \mathrm{VCM}$, acts as a chemical competitor and is bound to both PPO and POD active sites, inhibiting enzymatic activities [40], further contributing to reduced enzyme activity as a result of a decreased $\mathrm{pH}$ [41]. In the case of $\mathrm{RE}$, phytic acid may be responsible for the mechanism of suppression. In addition, phytic acid is known to inhibit enzymes, such as PPO and POD [42]. These results suggest that the inhibition of both enzyme activities could result in the improvement of browning of both $4 \%$ VCM and VR. 
PPO and POD, the phenolic oxidase enzymes, may affect browning in apples [43]. PPO and POD catalyzed the oxidation of monophenols to quinones which are browning pigments [44]. In this context, the activities in the 4\% VCM and VR groups tended to decrease over time compared to the DW group. The activities tended to decrease from day 6 in the 4\% VCM group and from day 3 in the VR group (Figure $4 \mathrm{~b}, \mathrm{c}$ ). The results of the correlation between oxidase and TPC show that the initial decrease range in VCM was lower than DW and the initial decrease range in VR is lower than in VCM. (Figure 4d,e). As a result, PPO activity was inhibited by phytic acid, the main component of RE, and the results were similar to those of previous studies [42].

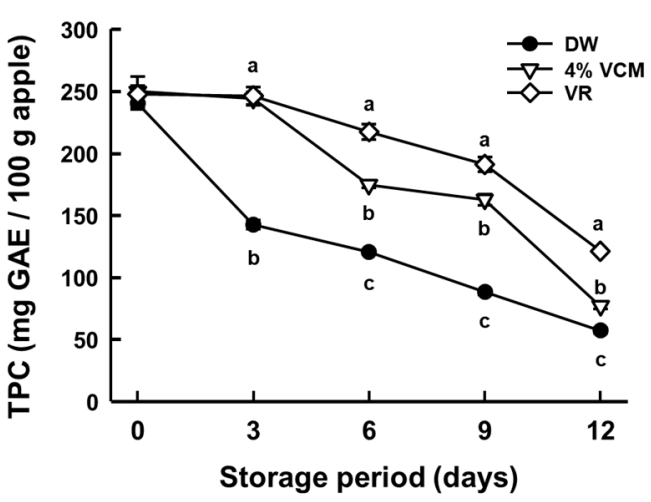

(a)

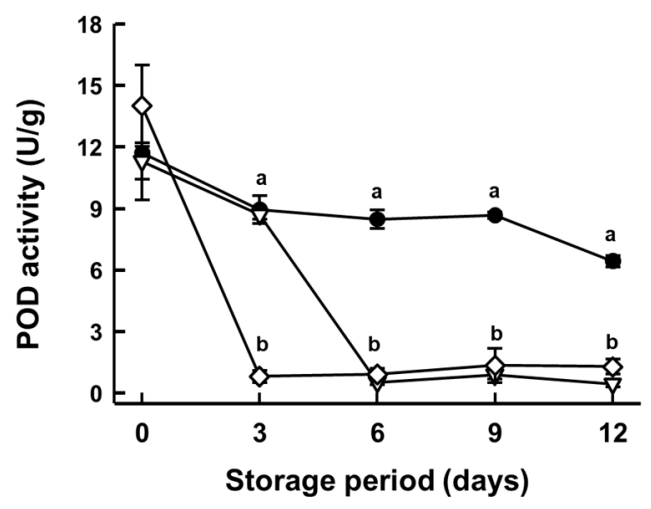

(c)

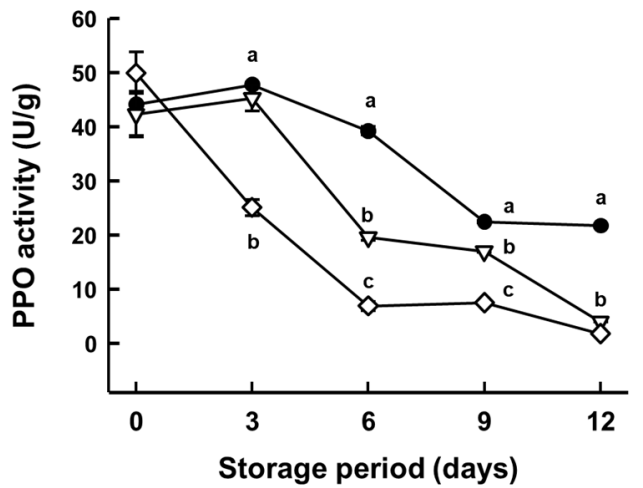

(b)

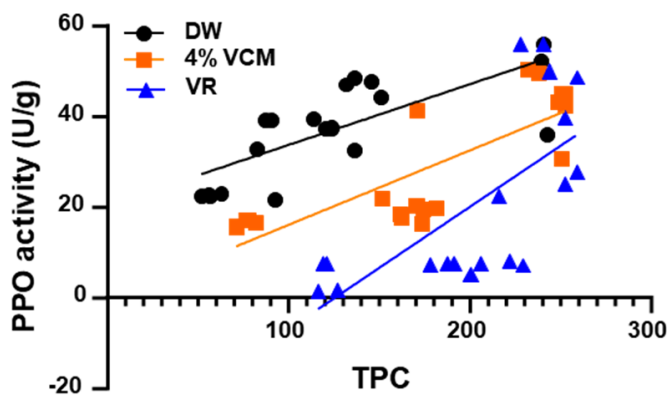

(d)

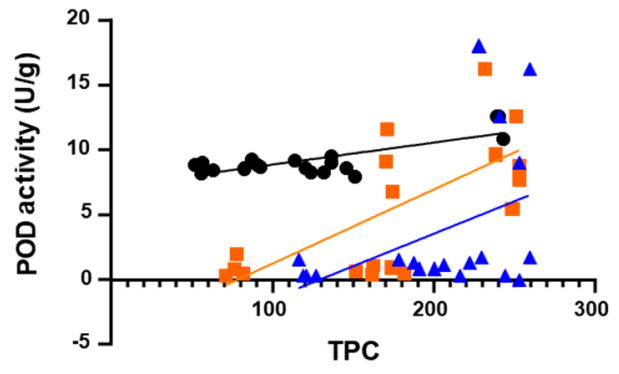

(e)

Figure 4. Analysis of TPC and phenolic oxidase activity in freshly cut apples. Differences in TPC, PPO, and POD activity changes in freshly cut apples soaked on days $0,3,6,9$, and 12. (a) TPC, (b) PPO activity, and (c) POD activity. Statistical significance was determined by one-way ANOVA (mean \pm SE, $n=3$ ). Pearson's correlation coefficient TPC and PPO (d), TPC and POD (e). 
The content of polyphenols in apples is an important contributor to the surface browning of freshly cut apples [45]. Browning enzymes convert polyphenols of fruit to quinones and reduce the total polyphenols. Eventually, browning reduces substrates such as polyphenols, which can accordingly reduce oxidative enzyme activity [46]. Figure 4 shows that VR inhibits PPO and POD and prevents the loss of total polyphenols. Similarly, a previous study reported that the levels of total polyphenol, proanthocyanidin, chlorogenic acid, and catechin in apples were negatively correlated with PPO activity [47].

\subsection{Effects of Anti-Browning Reagent on Microbial Growth in Apples}

Freshly cut fruit is a fertile environment for the growth of microorganisms due to the large amounts of water and energy sources [48]. The anti-browning treatment of freshly cut fruits can be used to inhibit degenerative and pathogenic microbial growth [39].

As shown in Figure 5, treatment with RE $\left(4.39 \times 10^{4} \pm 0.32\right)$ was more effective for microbial growth inhibition than $3 \% \operatorname{VCM}\left(6.15 \times 10^{4} \pm 0.4\right)$. However, the best strategy to inhibit microbial growth in freshly cut apple slices was through a combined (VR) application $\left(4.25 \times 10^{3} \pm 0.15\right)$. In addition, E. coli was not detected in any of the treated groups (data not shown).

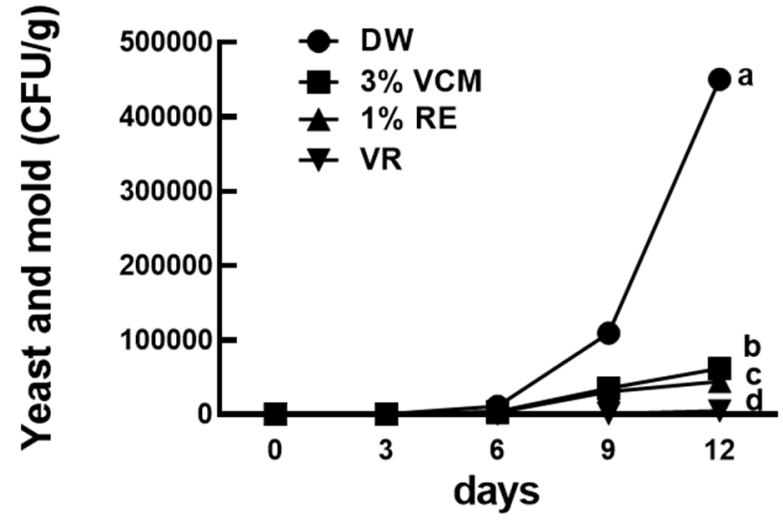

Figure 5. Changes in the counts of yeast and mold (CFU/g) in freshly cut apples during storage at $4{ }^{\circ} \mathrm{C}$. The freshly cut apples are coated with DW, VCM 3\%, RE, and VR. One-way ANOVA determined statistical significance (mean $\pm \mathrm{SE}, \mathrm{n}=3$ ).

Ascorbic acid, a major component of VCM, has been reported to be an effective bactericidal agent [49] and has shown inhibitory effects on the growth of E. coli and Streptococcus aureus [50]. RE is a rich source of phytic acid, which can interfere with bacterial membrane integrity and effectively degrade the membrane of gram-positive bacteria [51]. The six reactive phosphate groups of phytic acid are known to break down the extracellular membrane by chelation of the divalent cations of lipopolysaccharides [52]. As a result of the experiment, the growth of microorganisms in all treatment groups was inhibited at a higher degree compared to that of DW. The microbial growth of freshly cut apples was more effectively inhibited after VR treatment compared to 3\% VCM treatment and $1 \%$ RE treatment. In particular, VR treatment reduced the number of microorganisms approximately 10-fold compared to 1\% RE treatment (Figure 5).

\subsection{Sensory Evaluation with VCM and RE Combination}

Sensory evaluation was conducted for the overall acceptability, sweetness, and sourness of the treated freshly cut apples. The sensory evaluation was carried out using previously optimized concentrations of 4\% VCM and VR.

As shown in Figure 6, the VR group scored higher in overall preference than the $4 \%$ VCM group. In particular, the VR group showed significantly higher scores for sweetness and sourness than the $4 \%$ VCM group. These results could be attributed to the inhibition of moisture diffusion by anti-browning agents [53]. Therefore, coated freshly cut apples treated with VR appeared to have improved palatability. 


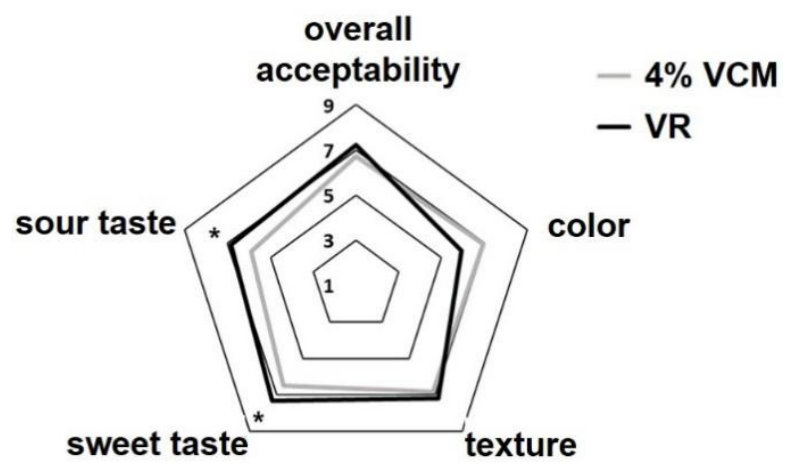

Figure 6. Analysis of sensory evaluation characteristics of apples by anti-browning reagents. Sensory analysis results for apple treated with $4 \%$ VCM and VR. Statistical significance compared with the $4 \%$ VCM and VR group was determined by the Student's $t$-test $\left({ }^{*} p<0.05\right)$.

\section{Conclusions}

In conclusion, the combination of RE with VCM was confirmed to be a synergistic anti-browning agent, compared to VCM alone, a widely used commercial anti-browning reagent. VR suppressed the browning reaction in freshly cut apples without significant changes in the Brix, $\mathrm{pH}$, and sensory preference indicators. In addition, the inhibition of PPO activity in freshly cut apples prevented the browning reaction and reduced the total polyphenol content. It was also confirmed that RE could increase the shelf life by inhibiting the growth of microorganisms. Taken together, the results presented in this study suggest that the synergistic combination of VCM and RE maximizes the anti-browning effect in freshly cut apples which provides a practical application protocol. Moreover, the utilization of RE, which is an agricultural by-product, might have potential economic benefits.

Supplementary Materials: The following supporting information can be downloaded at: https:/ / www.mdpi.com/article/10.3390/agronomy12010086/s1, Table S1: Pearson's correlation coefficients among selected quality parameters like TPC and PPO, TPC and POD values.

Author Contributions: Data curation, S.H.L., S.M.B. and B.K.H.; Writing-original draft preparation, S.H.L.; Writing-review and editing, I.J., B.K.H., W.H., K.-A.H. and Y.J.K.; Visualization, S.H.L.; Supervision, B.K.H. and Y.J.K. All authors have read and agreed to the published version of the manuscript.

Funding: Not applicable.

Institutional Review Board Statement: Not applicable.

Informed Consent Statement: Not applicable.

Data Availability Statement: Not applicable.

Acknowledgments: This research was supported by the BK21 FOUR (Fostering Outstanding Universities for Research) funded by the Ministry of Education (MOE, Korea) and National Research Foundation of Korea (NRF).

Conflicts of Interest: The authors declare no conflict of interest.

\section{References}

1. Li, X.; Jiang, Y.; Li, W.; Tang, Y.; Yun, J. Effects of ascorbic acid and high oxygen modified atmosphere packaging during storage of fresh-cut eggplants. Food Sci. Technol. Int. 2014, 20, 99-108. [CrossRef]

2. Sinha, N.K. Apples and pears: Production, physicochemical and nutritional quality, and major products. In Handbook of Fruits and Fruit Processing; John Wiley \& Sons: Hoboken, NJ, USA, 2012; pp. 365-383.

3. Shrestha, L.; Kulig, B.; Moscetti, R.; Massantini, R.; Pawelzik, E.; Hensel, O.; Sturm, B. Optimisation of physical and chemical treatments to control browning development and enzymatic activity on fresh-cut apple slices. Foods 2020, 9, 76. [CrossRef]

4. Li, W.; Li, L.; Cao, Y.; Lan, T.; Chen, H.; Qin, Y. Effects of PLA film incorporated with ZnO nanoparticle on the quality attributes of fresh-cut apple. Nanomaterials 2017, 7, 207. [CrossRef] [PubMed] 
5. Cofelice, M.; Lopez, F.; Cuomo, F. Quality control of fresh-cut apples after coating application. Foods 2019, 8, 189. [CrossRef] [PubMed]

6. Zhao, P.; Li, W.; Zhen, C.; Wang, K.; Qin, Z.; Gao, H. Transcriptomic analysis of the effects of $\gamma$-aminobutyric acid treatment on browning and induced disease resistance in fresh-cut apples. Postharvest Biol. Technol. 2021, 181, 111686. [CrossRef]

7. Liu, X.; Wang, T.; Lu, Y.; Yang, Q.; Li, Y.; Deng, X.; Liu, Y.; Du, X.; Qiao, L.; Zheng, J. Effect of high oxygen pretreatment of whole tuber on anti-browning of fresh-cut potato slices during storage. Food Chem. 2019, 301, 125287. [CrossRef]

8. Putnik, P.; Bursać Kovačević, D.; Herceg, K.; Levaj, B. Influence of antibrowning solutions, air exposure, and ultrasound on color changes in fresh-cut apples during storage. J. Food Process. Preserv. 2017, 41, e13288. [CrossRef]

9. Pizzocaro, F.; Torreggiani, D.; Gilardi, G. Inhibition of apple polyphenoloxidase (PPO) by ascorbic acid, citric acid and sodium chloride. J. Food Process. Preserv. 1993, 17, 21-30. [CrossRef]

10. Fan, X.; Sokorai, K.; Phillips, J. Development of antibrowning and antimicrobial formulations to minimize Listeria monocytogenes contamination and inhibit browning of fresh-cut "Granny Smith" apples. Postharvest Biol. Technol. 2018, 143, 43-49. [CrossRef]

11. Ncama, K.; Magwaza, L.S.; Mditshwa, A.; Tesfay, S.Z. Plant-based edible coatings for managing postharvest quality of fresh horticultural produce: A review. Food Packag. Shelf Life 2018, 16, 157-167. [CrossRef]

12. Mayer, A.M. Polyphenol oxidases in plants-recent progress. Phytochemistry 1986, 26, 11-20. [CrossRef]

13. Zhang, X.; Shao, X. Characterisation of polyphenol oxidase and peroxidase and the role in browning of loquat fruit. Czech J. Food Sci. 2015, 33, 109-117. [CrossRef]

14. Serra, S.; Anthony, B.; Boscolo Sesillo, F.; Masia, A.; Musacchi, S. Determination of Post-Harvest Biochemical Composition, Enzymatic Activities, and Oxidative Browning in 14 Apple Cultivars. Foods 2021, 10, 186. [CrossRef] [PubMed]

15. Katiyo, W.; Yang, R.; Zhao, W.; Hua, X.; Gasmalla, M.A.A. Optimization of combined pulsed electric fields and mild temperature processing conditions for red apple juice polyphenol oxidase and peroxidase inactivation. Adv. J. Food Sci. Technol. 2014, 6, 638-646. [CrossRef]

16. Özdemir, K.S.; Gökmen, V. Effect of chitosan-ascorbic acid coatings on the refrigerated storage stability of fresh-cut apples. Coatings 2019, 9, 503. [CrossRef]

17. Sharif, M.K.; Butt, M.S.; Anjum, F.M.; Khan, S.H. Rice bran: A novel functional ingredient. Crit. Rev. Food Sci. Nutr. 2014, 54, 807-816. [CrossRef]

18. Sohail, M.; Rakha, A.; Butt, M.S.; Iqbal, M.J.; Rashid, S. Rice bran nutraceutics: A comprehensive review. Crit. Rev. Food Sci. Nutr. 2017, 57, 3771-3780. [CrossRef]

19. Arab, F.; Alemzadeh, I.; Maghsoudi, V. Determination of antioxidant component and activity of rice bran extract. Sci. Iran. 2011, 18, 1402-1406. [CrossRef]

20. Mahunu, G.K.; Zhang, H.; Yang, Q.; Zhang, X.; Li, D.; Zhou, Y. Improving the biocontrol efficacy of Pichia caribbica with phytic acid against postharvest blue mold and natural decay in apples. Biol. Control 2016, 92, 172-180. [CrossRef]

21. Moure, A.; Cruz, J.M.; Franco, D.; Domínguez, J.M.; Sineiro, J.; Domínguez, H.; Núñez, M.J.; Parajó, J.C. Natural antioxidants from residual sources. Food Chem. 2001, 72, 145-171. [CrossRef]

22. Romani, V.P.; Hernández, C.P.; Martins, V.G. Pink pepper phenolic compounds incorporation in starch/protein blends and its potential to inhibit apple browning. Food Packag. Shelf Life 2018, 15, 151-158. [CrossRef]

23. Sukhonthara, S.; Kaewka, K.; Theerakulkait, C. Inhibitory effect of rice bran extracts and its phenolic compounds on polyphenol oxidase activity and browning in potato and apple puree. Food Chem. 2016, 190, 922-927. [CrossRef] [PubMed]

24. Suttirak, W.; Manurakchinakorn, S. Potential application of ascorbic acid, citric acid and oxalic acid for browning inhibition in fresh-cut fruits and vegetables. Walailak J. Sci. Technol. WJST 2010, 7, 5-14.

25. Liu, X.; Ren, J.; Zhu, Y.; Han, W.; Xuan, H.; Ge, L. The preservation effect of ascorbic acid and calcium chloride modified chitosan coating on fresh-cut apples at room temperature. Colloids Surf. A Physicochem. Eng. Asp. 2016, 502, 102-106. [CrossRef]

26. Olivas, G.; Mattinson, D.; Barbosa-Cánovas, G. Alginate coatings for preservation of minimally processed 'Gala'apples. Postharvest Biol. Technol. 2007, 45, 89-96. [CrossRef]

27. Eshghi, S.; Hashemi, M.; Mohammadi, A.; Badii, F.; Mohammadhoseini, Z.; Ahmadi, K. Effect of nanochitosan-based coating with and without copper loaded on physicochemical and bioactive components of fresh strawberry fruit (Fragaria $x$ ananassa Duchesne) during storage. Food Bioprocess Technol. 2014, 7, 2397-2409. [CrossRef]

28. Kim, A.N.; Lee, K.Y.; Kim, H.J.; Chun, J.; Kerr, W.L.; Choi, S.G. Effect of grinding at modified atmosphere or vacuum on browning, antioxidant capacities, and oxidative enzyme activities of apple. J. Food Sci. 2018, 83, 84-92. [CrossRef]

29. Bradford, M.M. A rapid and sensitive method for the quantitation of microgram quantities of protein utilizing the principle of protein-dye binding. Anal. Biochem. 1976, 72, 248-254. [CrossRef]

30. Tao, R.; Zhang, F.; Tang, Q.-J.; Xu, C.-S.; Ni, Z.-J.; Meng, X.-H. Effects of curcumin-based photodynamic treatment on the storage quality of fresh-cut apples. Food Chem. 2019, 274, 415-421. [CrossRef]

31. Solval, K.M.; Xiang, B.; Lee, Y.S. Combined effects of calcium ascorbate treatment and modified atmosphere packaging to improve quality retention of fresh-cut cantaloupes. J. Appl. Packag. Res. 2019, 11, 5.

32. Adhikary, T.; Gill, P.S.; Jawandha, S.K.; Bhardwaj, R.D.; Anurag, R.K. Browning and quality management of pear fruit by salicylic acid treatment during low temperature storage. J. Sci. Food Agric. 2021, 101, 853-862. [CrossRef]

33. Singh, S. Method for Preserving Foodstuff European Patent EP1301084B1, 15 June 2001. 
34. Chowhan, Z. pH-solubility profiles of organic carboxylic acids and their salts. J. Pharm. Sci. 1978, 67, 1257-1260. [CrossRef] [PubMed]

35. Rovito, M.A.; De Bonis, M.V.; Ruocco, G. COLDwave TM processing: Cold jet impingement to control bio-substrate drying by microwave and preserve its quality. Heat Mass Transf. 2019, 55, 953-963. [CrossRef]

36. Kahraman, O.; Malvandi, A.; Vargas, L.; Feng, H. Drying characteristics and quality attributes of apple slices dried by a non-thermal ultrasonic contact drying method. Ultrason. Sonochem. 2021, 73, 105510. [CrossRef]

37. Buta, J.G.; Moline, H.E.; Spaulding, D.W.; Wang, C.Y. Extending storage life of fresh-cut apples using natural products and their derivatives. J. Agric. Food Chem. 1999, 47, 1-6. [CrossRef]

38. Chen, C.; Hu, W.; He, Y.; Jiang, A.; Zhang, R. Effect of citric acid combined with UV-C on the quality of fresh-cut apples. Postharvest Biol. Technol. 2016, 111, 126-131. [CrossRef]

39. Olivas, G.; Barbosa-Cánovas, G. Edible coatings for fresh-cut fruits. Crit. Rev. Food Sci. Nutr. 2005, 45, 657-670. [CrossRef]

40. Nelson, L.; Cox, M.M.; Freeman, W. Lehninger Principles of Biochemistry. Third; Worth Publishers: New York, NY, USA, 2000.

41. Villamil-Galindo, E.; Van de Velde, F.; Piagentini, A.M. Extracts from strawberry by-products rich in phenolic compounds reduce the activity of apple polyphenol oxidase. LWT 2020, 133, 110097. [CrossRef]

42. Du, Y.; Dou, S.; Wu, S. Efficacy of phytic acid as an inhibitor of enzymatic and non-enzymatic browning in apple juice. Food Chem. 2012, 135, 580-582. [CrossRef]

43. Amiot, M.J.; Tacchini, M.; Aubert, S.; Nicolas, J. Phenolic composition and browning susceptibility of various apple cultivars at maturity. J. Food Sci. 1992, 57, 958-962. [CrossRef]

44. Moon, K.M.; Kwon, E.-B.; Lee, B.; Kim, C.Y. Recent trends in controlling the enzymatic browning of fruit and vegetable products. Molecules 2020, 25, 2754. [CrossRef]

45. Guardo, M.D.; Tadiello, A.; Lorenz, G.; Masuero, D.; Vrhovsek, U.; Velasco, R.; Costa, F.; Farneti, B.; Costa, G. Multidisciplinary approach provides novel insight about fruit flesh browning physiology in apple (Malus $\times$ domestica Borkh.). In Proceedings of the III International Symposium on Molecular Markers in Horticulture 1100, Trento, Italy, 25-27 September 2013; pp. 161-166.

46. Lu, S.; Luo, Y.; Feng, H. Inhibition of apple polyphenol oxidase activity by sodium chlorite. J. Agric. Food Chem. 2006, 54, 3693-3696. [CrossRef] [PubMed]

47. Ye, S.; Yao, Y.-X.; Heng, Z.; Du, Y.-P.; Feng, C.; Shu-Wei, W. Polyphenolic compound and the degree of browning in processing apple varieties. Agric. Sci. China 2007, 6, 607-612.

48. Rojas-Graü, M.A.; Raybaudi-Massilia, R.M.; Soliva-Fortuny, R.C.; Avena-Bustillos, R.J.; McHugh, T.H.; Martín-Belloso, O. Apple puree-alginate edible coating as carrier of antimicrobial agents to prolong shelf-life of fresh-cut apples. Postharvest Biol. Technol. 2007, 45, 254-264. [CrossRef]

49. Myrvik, Q.N.; Volk, W.A. Comparative study of the antibacterial properties of ascorbic acid and reductogenic compounds. J. Bacteriol. 1954, 68, 622. [CrossRef]

50. Selim, S.A.; El Alfy, S.M.; Abdel Aziz, M.; Mashait, M.S.; Warrad, M.F. Evolution of bactericidal activity of selected food additives against food borne microbial pathogens. Biosci. Biotechnol. Res. Asia 2012, 9, 7-17. [CrossRef]

51. Zhou, Q.; Zhao, Y.; Dang, H.; Tang, Y.; Zhang, B. Antibacterial effects of phytic acid against foodborne pathogens and investigation of its mode of action. J. Food Prot. 2019, 82, 826-833. [CrossRef]

52. Oatway, L.; Vasanthan, T.; Helm, J.H. Phytic acid. Food Rev. Int. 2001, 17, 419-431. [CrossRef]

53. Farina, V.; Passafiume, R.; Tinebra, I.; Palazzolo, E.; Sortino, G. Use of aloe vera gel-based edible coating with natural antibrowning and anti-oxidant additives to improve post-harvest quality of fresh-cut 'fuji' apple. Agronomy 2020, 10, 515. [CrossRef] 